\title{
Analytical Model for the Prediction of Performance of a Solar Driven Diffusion Absorption Cooling System
}

\author{
B. Gurevich* and A. Zohar \\ Shamoon College of Engineering, Department of Mechanical Engineering, Ashdod, Israel \\ E-mail: "bellagu@sce.ac.il
}

Received 1 May 2021, Revised 27 June 2021, Accepted 16 July 2021

\begin{abstract}
In contrast to standard vapor compression cooling systems, diffusion absorption refrigeration (DAR) systems are heatdriven and contain no moving parts. Solar diffusion absorption cooling systems can extract heat from a cooling chamber without electricity, enabling food and medicine to be cooled in remote places where there is high solar radiation with unavailable or unreliable electricity. This work aims to model the performance of a solar-driven DAR system with an evacuated tubes collector. The model inputs were the local hourly ambient temperature and solar irradiance for the time of June to August in Ashdod, Israel. Also, collector data, ammonia concentration in the solution, evaporator temperature and the DAR system geometry were considered. The model results showed that as the generator heat input increased rapidly the evaporator cooling capacity was kept almost constant for a given concentration and collector area. This resulted in reduction in the COP values at peak hour. An increase in the collector area had more impact on the heat applied to the generator and not resulted in a significant growth of the cooling capacity, thus, the authors concluded that for optimal COP it is advised to operate the system with lower collector areas.
\end{abstract}

Keywords: DAR systems; solar cooling; evacuated tubes collector.

\section{Introduction}

Diffusion absorption refrigeration (DAR) systems were invented by [1] and [2]. These systems are heat-driven and have no moving mechanical parts, such as a compressor or a pump. The working fluid is a mixture of a coolant and an absorbent along with an inert gas. The core part of such systems is the bubble pump, where heating, pumping of the binary solution and the separation of the coolant from the solution occurs. The bubble pump is a heated tube (length $\mathrm{L}$ and diameter D) connecting between two reservoirs (Figure. 1 ). When heat is applied at the bottom of the bubble pump, some of the coolant forms bubbles that carry the liquid solution up the lifting tube. The gaseous coolant is separated from the liquid solution in the upper reservoir (separator). In DAR systems, the bubble pump is the device that creates the circulation of the binary solution.

The coefficient of performance (COP) values of DAR systems are low and in the range of $0.1-0.15$. Because bubble pumps are at the core of DAR systems, they have been studied for several years. These studies sought to collect more comprehensive data to enable the design of DARs with higher COP values.

Delano [3] assumed slug flow in the bubble pump, relying on [4], who stated that bubble pumps operate most efficiently in the slug flow regime. The maximum tube diameter in which slug flow occurs was defined. Note, for a given fluid in a tube of diameter greater than that predicted by [4], slug flow will never occur. Theoretical analysis (applying mass and momentum conservation laws on the whole bubble pump control volume and on the control volume which is heated and assuming laminar slug flows) provided information regarding the dependence of bubble pump performance on parameters such as heat inputs, tube diameters, and submergence ratios (the ratio between the liquid level in the bubble pump to the length of the bubble pump). With an increasing submergence ratio, the relative height to which the pump must lift the liquid decreased, the liquid flow rate increased. For a fixed submergence ratio, the liquid mass flow rate increased with increasing heat input, reached a maximum, and then decreased with further heat input increase. This maximum flow occurred when the increase in the frictional pressure drop caused by the increased vapor flow rate exceeded the increased buoyancy effect of the vapor to pump the liquid ([5]). As the diameter increased, the friction factor decreased, thereby increasing the efficiency of the pump. However, the diameter was limited by [4].

Koyfman et al. [6] designed and built a successfully operating continuous experimental system. A solution of organic solvent and hydrochlorofluorocarbon refrigerant was used as the working fluid - the designed system allowed Steady-State, Steady-Flow (SSSF) operation. The experiments were performed while some of the parameters affecting the bubble pump performance were changed. Increasing the heat input to the generator increased the rich solution flow rate, as well as an increase in the poor solution mass flow rates (at the outlets of the three control volumes) through the system. The differences between the values of the mass flow rate at a given heat input are directly related to the back absorption in both the bubble pump tube and the poor solution heat exchanger. The back absorption of the refrigerant to the solution reduced both bubble pump efficiency and cycle performance. The results showed that any change in the motive head (the height of the rich solution level in the reservoir as illustrated at Figure 1 as $\mathrm{H}$ ) of the system would cause a change in the working conditions of 
the bubble pump (outlet temperature, operating pressure, and flow rates). Increasing the motive head decreased both the pump head and increased the rich solution flow rate. This resulted in decreased outlet fluid temperature at the generator outlet, for the same heat input. In turn, the outlet fluid temperature decrease caused a decrease in the amount of desorbed gas from the solution in the generator. The experimental results also showed that to achieve the highest gas mass flow rate, it would be advisable to operate the system with the motive head as low as possible. Lowering the motive head reduced the mass flow and the velocity of the fluid through the generator. The motive head changes also changed the minimal heat input required to sustain a continuous flow through the system.

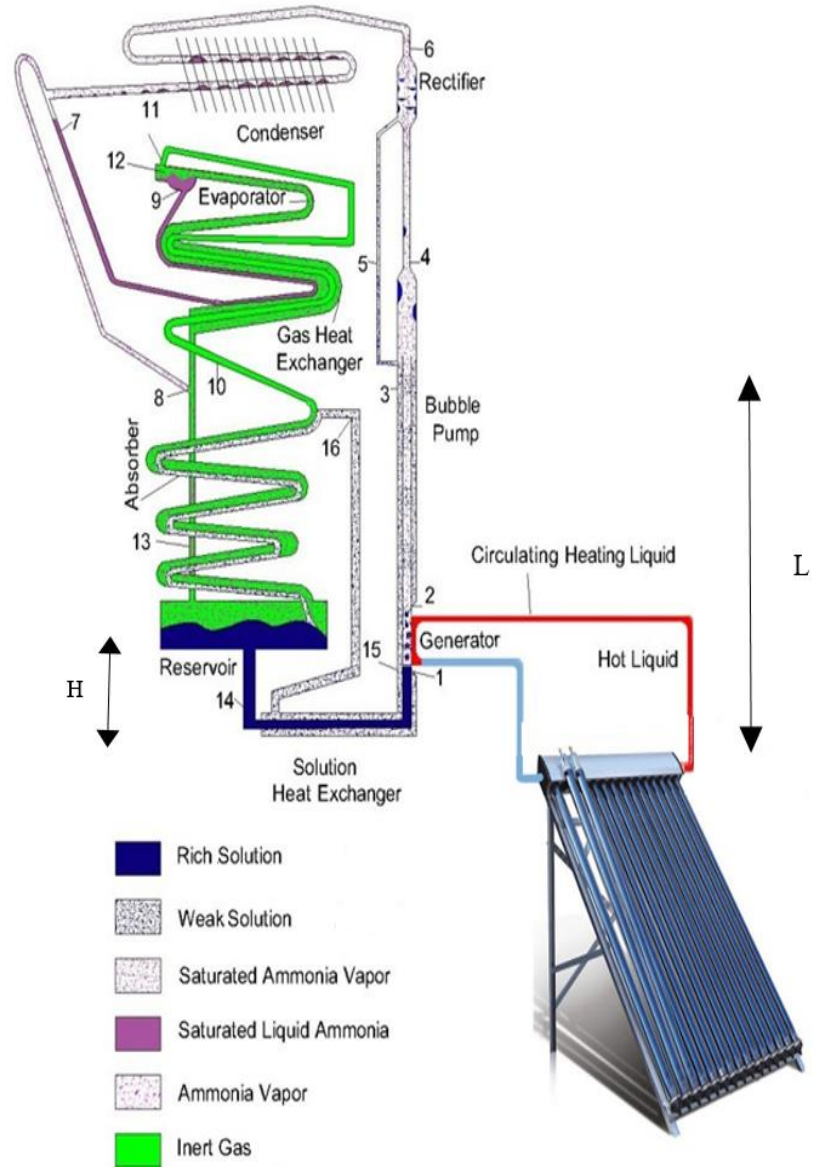

Figure 1. Schematic design of the system

Dammak et al. [7] numerically studied the optimization of a solar driven bubble pump connected to a flat collector operating with ammonia-water-helium. The model has taken into consideration the meteorological data of Gabes (Tunisia). The optimum efficiency was achieved for a bubble pump with a tube diameter of $6 \mathrm{~mm}$ and a length of 1.5 meters. The optimum solar collector inclination angle was in the range of $30^{\circ}$ to $50^{\circ}$ with a submergence ratio between 0.2 and 0.3 . The authors did not consider that flat plate collectors are more suitable for low-temperature applications such as domestic water heating and space heating.

Evacuated tube solar collectors are preferable for higher temperatures that are required to circulate the binary solution in DAR systems, as shown by [8].

A numerical model for a bubble pump was developed by Gurevich [9] and allowed prediction of the amounts of the separated refrigerant for a specific submergence value within the values of heat input where lifting occurs. The model also correlated the amount of applied heat and the rich solution mass flow rates.

Freeman et al. [10] tested the operation of a solar DAR operating with ammonia-water-hydrogen in Chennai, India. Various heat pipe solar collectors were used in their experimental work; their area was $1 \mathrm{~m}^{2}$. The authors have reported that the maximum COP achieved was strongly dependent on the system pressure. The measured generator temperature during the day was $150^{\circ} \mathrm{C}$. The diurnal simulation was based on empirical equations.

Thermodynamic models for two configurations of DAR cycles (with and without condensate sub-cooling before the evaporator entrance) were developed by Zohar et al. [11]. The performances of the two cycles were analyzed and compared by computer simulation. It was found that the best performances would be obtained when the ammonia mass fractions of the rich solution varied in the range of $0.25-0.4$. Recommended values for the ammonia mass fractions of the rich and weak solutions are $0.3-0.4$ and 0.1 , respectively. A model of [12] showed that optimal COP for these concentrations is achieved when generator temperature ranges from $195^{\circ} \mathrm{C}$ to $205^{\circ} \mathrm{C}$.

Zohar et al. [13] numerically studied the performance of a DAR system with three configurations of generator and bubble pump. They found that the best performance occurred when the heat was supplied directly into the rich solution and the bubble pump was attached to the returning poor solution.

Computer simulation conducted by [14] examined the COPs of five different refrigerants, each working with DMAC as an absorbent. The results were compared to an ammonia - water system working at similar conditions. For an ammonia-water system, the minimal generator temperature was $150^{\circ} \mathrm{C}$. Among the organic working fluids, the DMAC-R22 system provided the highest COP (0.224), low circulation ratio, and intermediate system pressure $(15.3$ bar). The generator temperatures had to be above $143^{\circ} \mathrm{C}$ and evaporator temperatures above $9^{\circ} \mathrm{C}$.

Previous theoretical works have studied either the DAR system analytically without taking into consideration the geometry of the bubble pump. Also the present research takes into consideration the site location weather and irradiance data together with the evacuated tube solar collector.

\section{Model}

The present research relies on the bubble pump model developed by [9], DAR theoretical model of [11] and evacuated solar collector heat balance. The model simulates am ammonia-water-helium DAR system heated by an evacuated solar collector.

The model assumptions were:

- The condenser and the reservoir temperatures were assumed to be equal.

- The condenser temperature was assumed to be $5^{\circ} \mathrm{C}$ higher than the ambient temperature.

- Poor Solution and vapor bubbles were assumed to leave the generator at the same temperature.

- The bubble pump and the solution heat exchanger were assumed to be insulated.

- The hydrostatic pressure was assumed to be relatively small and was, therefore, neglected.

- $\quad$ Pressure drops along the pipes were neglected. 
- The properties of gas mixtures were calculated according to the ideal gas mixture.

- The exit from the evaporator was the entrance to the reservoir.

- The ammonia leaving the rectifier (6) was assumed pure.

- The mixing at the entrance of the evaporator was assumed to be adiabatic.

- No absorption took place inside the reservoir.

- The rich solution entering the generator and the poor solution entering the absorber were assumed to be in a state of equilibrium enabling implementation of $P-T-\xi$ function.

- All the useful heat from the evacuated solar tube collector is equal to the generator heat input.

- The generator heat input causes an increase in the ammonia temperature.

The primary model equations are presented below. These equations are general mass, ammonia conservation and energy conservations.

Mass and energy balances on the generator:

$\dot{m}_{2}=\dot{m}_{3}+\dot{m}_{4}$

$\dot{m}_{2} \xi_{2}=\dot{m}_{3} \xi_{3}+\dot{m}_{4} \xi_{4}$

$\dot{Q}_{\text {gen }}=\dot{m}_{3} h_{3}+\dot{m}_{4} h_{4}-\dot{m}_{2} h_{2}$

Mass balance of the rectifier:

$\dot{m}_{4}=\dot{m}_{5}+\dot{m}_{6}$

$\dot{m}_{4} \xi_{4}=\dot{m}_{5} \xi_{5}+\dot{m}_{6} \xi_{6}$

$\dot{Q}_{\text {rec }}=\dot{m}_{5} h_{5}+\dot{m}_{6} h_{6}-\dot{m}_{4} h_{4}$

The circulation ratio is defined as:

$f=\frac{\dot{m}_{1}}{\dot{m}_{6}}$

Mass and energy balances on the condenser:

$$
\begin{aligned}
& \dot{m}_{6}=\dot{m}_{7} \\
& \dot{Q}_{\text {cond }}=\dot{m}_{7} X_{7} h_{7 f}+\dot{m}_{8}\left(1-X_{7}\right) h_{8 v}-\dot{m}_{6} h_{6}
\end{aligned}
$$

Mass and energy balances on the gas heat exchanger and the evaporator:

$$
\begin{aligned}
& \dot{m}_{12}=\dot{m}_{9}+\dot{m}_{11} \\
& \dot{m}_{13}=\dot{m}_{7}+\dot{m}_{10} \\
& \dot{m}_{13}=\dot{m}_{12} \\
& \dot{m}_{7}=\dot{m}_{9} \\
& \dot{m}_{11}=\dot{m}_{10}
\end{aligned}
$$

$$
\begin{aligned}
& \dot{Q}_{\text {evap }}=\dot{m}_{13 v} h_{13 v}+\dot{m}_{13 f} h_{13 f}+\ldots \\
& \dot{m}_{H e} c_{p_{H e}}\left(T_{13}-T_{12}\right)-\dot{m}_{12 v} h_{12 v}+\ldots \\
& +\dot{m}_{12 f} h_{12 f}+\dot{m}_{7} X_{7}\left(h_{9}-h_{7}\right)+\ldots \\
& +\dot{m}_{H e} c_{p_{H e}}\left(T_{11}-T_{10}\right)
\end{aligned}
$$

Mass and energy balances on the absorber and the reservoir:

$$
\begin{aligned}
& \dot{m}_{13}+\dot{m}_{16}=\dot{m}_{14}+\dot{m}_{10} \\
& \dot{m}_{13} \xi_{13}+\dot{m}_{16} \xi_{16}=\dot{m}_{14} \xi_{14}+\dot{m}_{10} \xi_{10} \\
& \dot{Q}_{a b s}=\dot{m}_{14} h_{14}+\dot{m}_{10 H e} h_{10 H e}+\dot{m}_{10} h_{10} \\
& -\dot{m}_{13 v} h_{13 v}-\dot{m}_{13 f} h_{13 f}-\dot{m}_{13 H e} h_{13 H e}-\dot{m}_{16} h_{16}
\end{aligned}
$$

Mass and energy balance on the solution heat exchanger:

Poor solution mass balance:

$\dot{m}_{15}=\dot{m}_{3}+\dot{m}_{5}$

$\dot{m}_{15}=\dot{m}_{16}$

Rich solution mass balance:

$\dot{m}_{1}=\dot{m}_{14}$

$\xi_{15}=\xi_{16} \quad$ and $\xi_{1}=\xi_{14}$

$\dot{m}_{1} h_{1}+\dot{m}_{16} h_{16}-\dot{m}_{14} h_{14}-\dot{m}_{15} h_{15}=0$

The COP of the DAR cooling system is defined as the ratio between the cooling capacity of the evaporator and the generator heat input.

$$
C O P=\frac{\dot{Q}_{\text {evap }}}{\dot{Q}_{\text {gen }}}
$$

The current research attempts to calculate all the mass flow rates as well as the generator temperature.

Thus, the additional equation that is implemented in the research is the bubble pump model suggested by [9].

$\frac{H}{L}=\frac{\dot{m}_{\text {rich }}^{2}}{\rho_{\text {rich }} \cdot g \cdot L} \cdot\left[\frac{1}{2 \rho_{\text {rich }} \cdot A_{D C}^{2}}+\frac{1}{A_{\text {gen }}^{2}} \cdot\left(\frac{1}{\rho_{T P}}-\frac{1}{\rho_{\text {rich }}}\right)\right]+\frac{\rho_{T P}}{\rho_{\text {rich }}}$

Lengths $H$ and $L$ are shown in Figure. 1.and $\rho_{\text {rich }}$ $\dot{\boldsymbol{m}}_{\text {rich }}$ are the rich solution's density and mass flow rate, respectively. In the present case $\dot{m}_{\text {rich }}=\dot{m}_{1}, \rho_{\text {rich }}=\rho_{1}$. $A_{D C}$ and $A_{g e n}$ are the areas of the downcomer and the generator, respectively. $\rho_{T P}$ is the density of the two-phase solution (desorbed coolant and the poor solution) and is defined as:

$$
\rho_{T P}=(1-\alpha) \rho_{L}+\alpha \rho_{G}
$$


$\rho_{L}$ and $\rho_{G}$ are the densities of the liquid and gas phases at point (2), respectively, and $\alpha$ is the void fraction, which is defined as:

$$
\alpha=\frac{V_{G S}}{C_{0} V_{m}+V_{G M}}
$$

The superficial gas velocity $V_{G S}$ is defined as the gas volumetric flowrate $Q_{G}$ at point (2), divided by the pipe's cross-section A:

$$
V_{G S}=\frac{Q_{G}}{A}
$$

The average mixture velocity $V_{m}$ is defined as:

$$
V_{m}=\frac{Q_{L}+Q_{G}}{A}
$$

There are several correlations to calculate the distribution parameter and the local drift velocity. For laminar flows, $C_{0} \approx 2$ [10-14]. According to [15], the local drift velocity, $V_{G M}$ is:

$$
V_{G M}=0.35 \sqrt{\frac{g D\left(\rho_{L}-\rho_{G}\right)}{\rho_{L}}}
$$

In order to correlate between the operational parameters of the evacuated solar collector and the DAR system $\dot{Q}_{u s e s f u l}$ should be calculated:

$$
\dot{Q}_{u s e s f u l}=I \cdot A_{A} \cdot \eta_{c}
$$

Where $I$ is the solar irradiance and $A_{A}$ is the collector absorber area. To calculate the collector's efficiency, $\eta_{c}$, the authors used datasheet of Apricus FPC-A26 evacuated tube solar collector:

$$
\eta_{c}=0.756-3.738 \frac{\left(T_{c}-T_{a m b}\right)}{I}-0.007 \frac{\left(T_{c}-T_{a m b}\right)^{2}}{I}
$$

where $T_{c}$ is the collector temperature.

The current model analyzes the solar DAR performance with respect to the site weather and solar irradiance.

The temperature and solar irradiance data of the site location (Ashdod, Israel) were collected from the Israeli Meteorological Services [15]. Data is presented in Table 1.

Table 1. Average temperature and irradiance hourly data dated from June to August in Ashdod Israel in 2020.

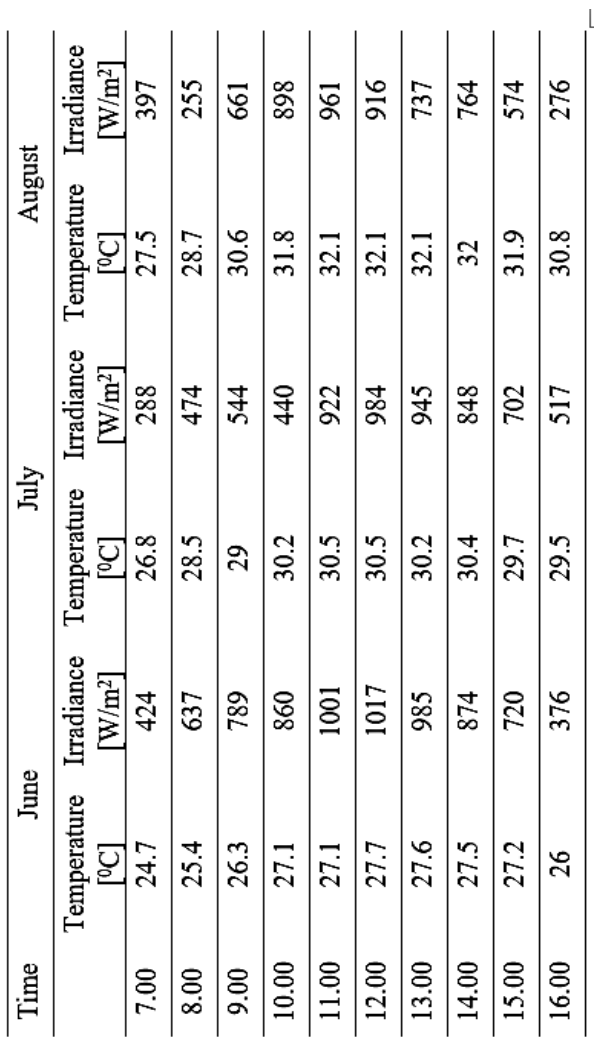

All model inputs are presented in Table 2.

\begin{tabular}{ll} 
Table 2: Model inputs. \\
\hline \multicolumn{1}{c}{ Input } & \multicolumn{1}{c}{ Value } \\
\hline Site Location & Ashdod, Israel \\
\hline Day of the year & $15 / 07 / 2020$ \\
\hline Collector absorber area, A & $1 \mathrm{~m}^{2}, 2 \mathrm{~m}^{2}, 4 \mathrm{~m}^{2}$ \\
\hline Ammonia concentration & $20 \%, 30 \%, 40 \%$ \\
\hline Evaporator temperature & $5^{0} \mathrm{C}$ \\
\hline Bubble pump inner diameter & $0.009 \mathrm{~m}$ \\
\hline Submergence ratio & 0.2
\end{tabular}

The results of the model are presented in the next section.

\section{Results}

The present research was performed on a DAR cycle presented in Figure 1 with the input values presented in Table 2 and hourly temperature and solar irradiance for the period of June to July in 2020. The model was solved by EES software that has built in functions for the calculation of ammonia-water binary solution. The results of the model are presented below.

Hourly generator heat input of the DAR system is presented in Figure 2. From 10 am, the heat input increases until it reaches a maximum value at noon. At this hour, the ambient temperature and the solar irradiance are the highest. From noon to $3 \mathrm{pm}$, the generator heat decreases. Maximum heat inputs are obtained for larger collector areas. The change in the ammonia concentration within the tested values has a negligible effect on the generator. Highest supplied heat inputs were for collector area of $4 \mathrm{~m}^{2}$, for ammonia concentrations ranging from 0.2 to 0.4 . There was not a significant difference in the heat inputs for the range of considered concentrations. 


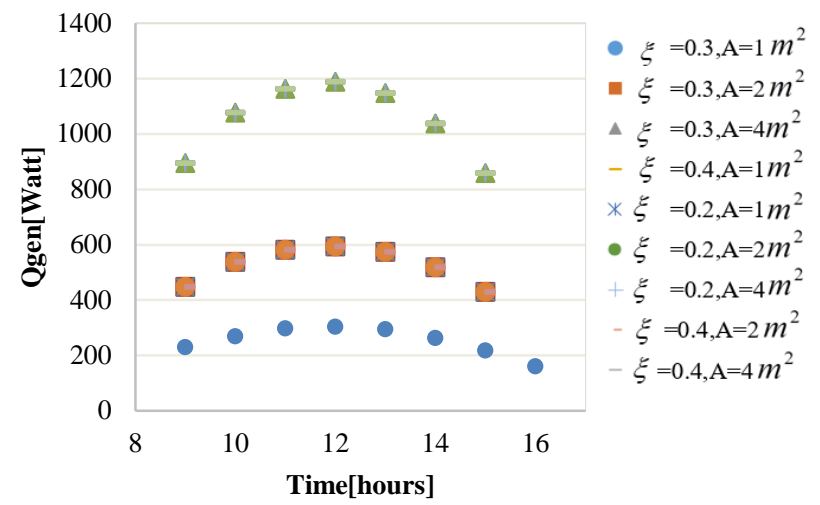

Figure 2. The generator heat as a function of time for various collector areas and ammonia concentrations, 15/07/2020.

The hourly cooling capacity is presented in Figure 3. The cooling capacity is decreasing until noon and then it increases as the applied heat is reduces. The ability of the bubble pump to generate vapor ammonia decreases with an increase in generator heat input. Maximum cooling capacities are achieved for higher collector areas. Again, the results barely depend on the concentration of the ammonia.

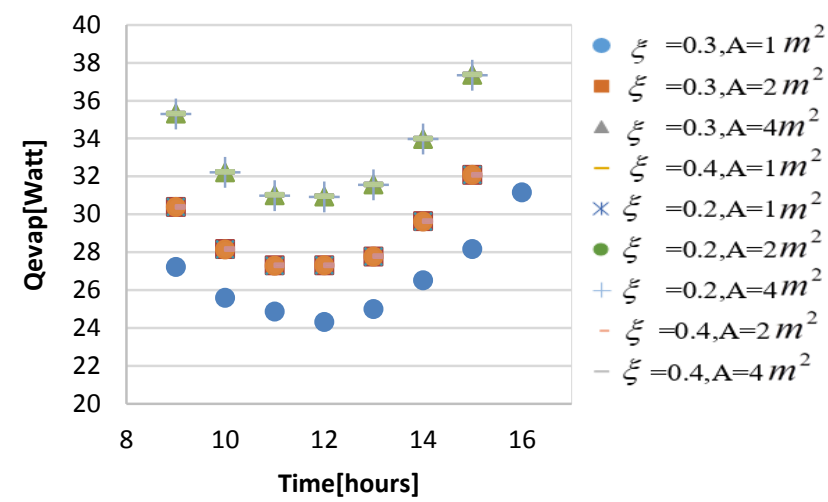

Figure 3. The cooling capacity as a function of time for various collector areas and ammonia concentrations, 15/07/2020.

The tendency of the COP to reach its minimum value at noon as seen in Figure 4 where the ambient temperature and the irradiance are at the peak can be explained by the circulation ratio. Best COP values are obtained for lowest collector area. The results do no depend on the ammonia concentration. Figure 5 demonstrates that the minimum values of the circulation ratio occur at noon. Best circulation results are achieved for lowest collector area. The explanation to this result is the two-phase flow pattern. During the morning, the irradiance increases and causes an increase in the supplied heat to the generator resulting in less rich solution flow rate and thus lesser ammonia vapor generation. At high heat inputs to the generator the flow pattern transitions from slug to churn flow. Therefore, additional heat at the generator reduces the efficiency of the bubble pump to generate more ammonia vapor that circulates in the condenser and the evaporator.

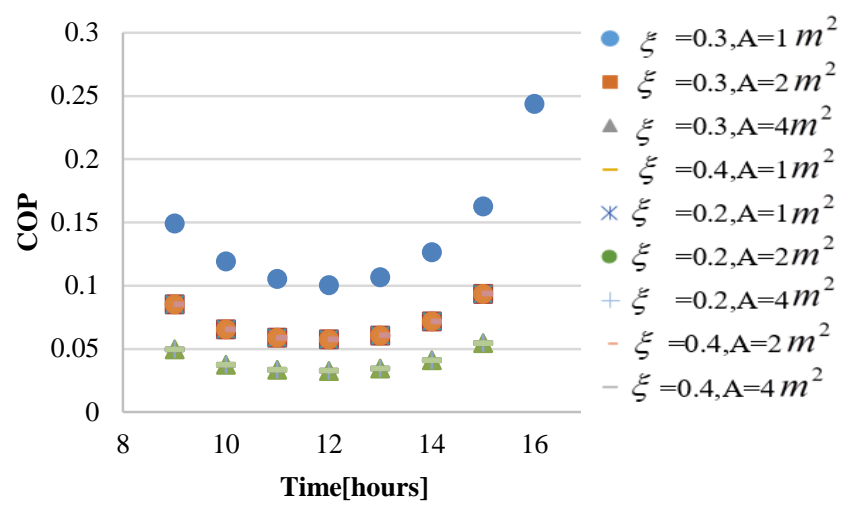

Figure 4. COP as a function of time for various collector areas and ammonia concentrations, 15/07/2020.
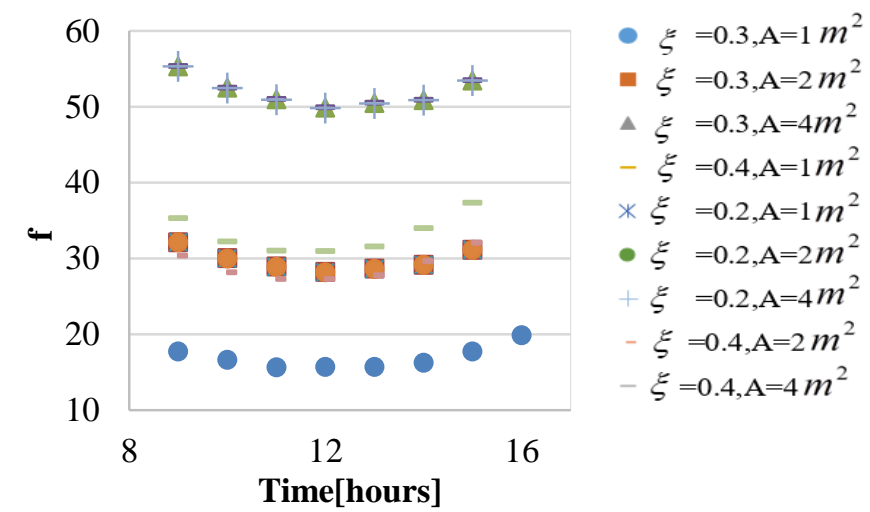

Figure 5. Circulation ratio as a function of time for various collector areas and ammonia concentrations, 15/07/2020.

Figures 6 to 9 present the model results for a period of three months starting from June until the end of August for ammonia concentration of 0.3 and collector area of $1 \mathrm{~m}^{2}$. The reason for the choice of these values is the previous results. Figures 2 to 5 have demonstrated that the system performance is poorly dependent on the ammonia concentrations within the chosen range and the area of $1 \mathrm{~m}^{2}$ was chosen due to highest COP values. Figure 6 and Figure 7 show an increase of the cooling capacity and a decrease of the heat applied to the generator (respectively) over the time. The cooling capacity increases as the heat applied to the generator decreases since slug flow regime governs at lower power inputs. An increase in cooling capacity along with a generator heat input decrease yield an increase of the COP values as the summer proceeds, as seen in Figure 8. The generator heat input is strongly dependent on the solar irradiance which is at its maximum values during June.

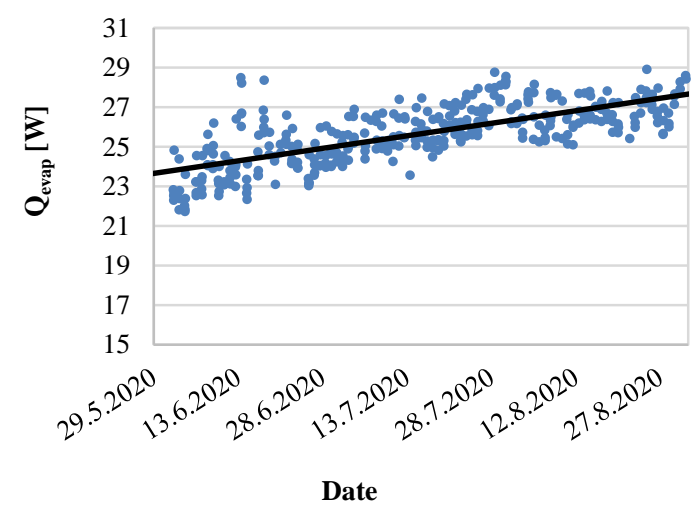

Figure 6. Daily cooling capacity of the evaporator, June to August 2020. 


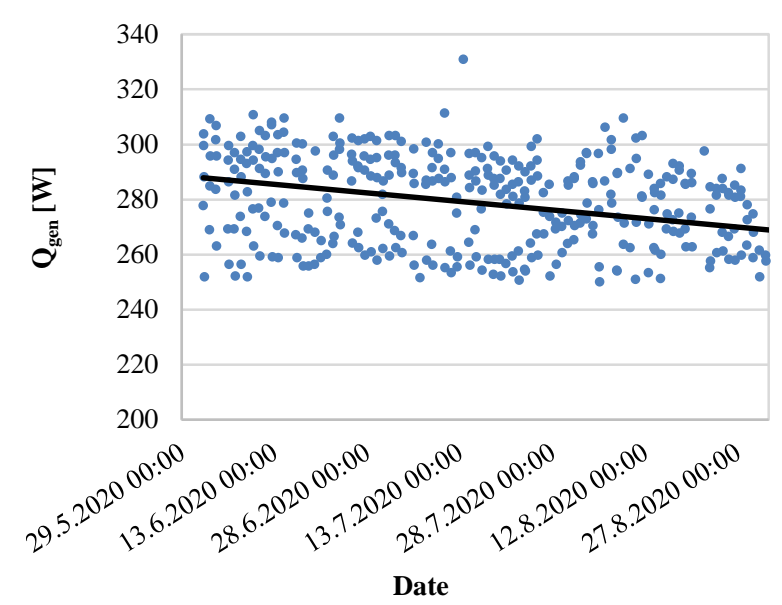

Figure 7. Daily generator heat input, June to August 2020.

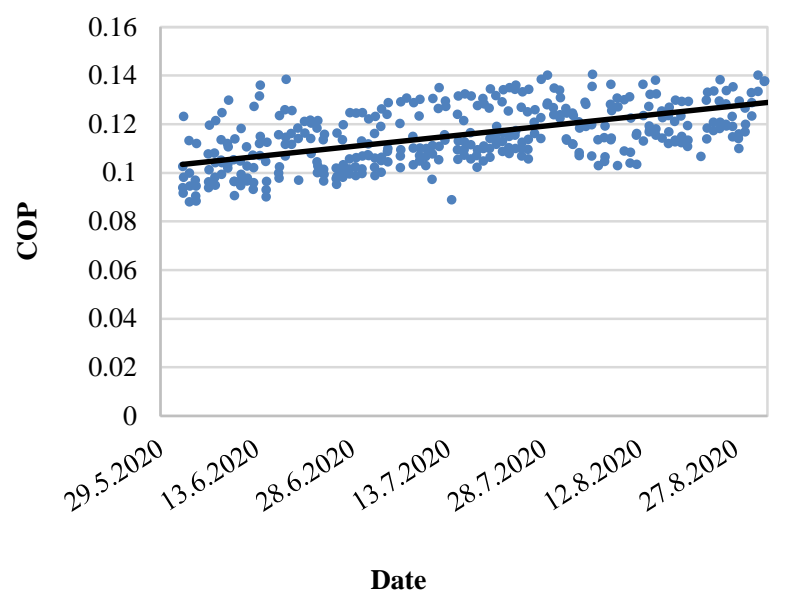

Figure 8. Daily COP, June to August 2020.

Figure 9 shows that along the summer, a stable operating generator temperature of $150^{\circ} \mathrm{C}$ to $170^{\circ} \mathrm{C}$ is obtained

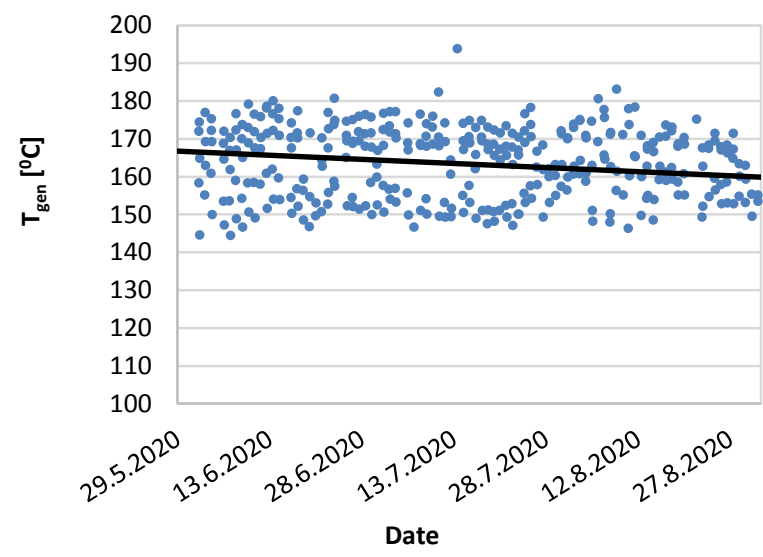

Figure 9. Daily COP, June to August 2020.

\section{Conclusions}

A solar powered DAR system by an evacuated tubes collector was analyzed, taking into considerations the site location, the measured ambient temperature and solar irradiance with respect to daily time. Evacuated tubes collector characteristics were also considered. Typical values of DAR COP's were observed and a stable generator temperature was received throughout the period tested. The results indicate that the increase in the generator heat input is at a greater magnitude than the ability of the bubble pump to generate more ammonia vapor. The direct result of this is the decrease in the hourly COP with the increase in the irradiance or in the collector's area. The ammonia concentrations that were tested did not show a significant influence on the COP values as well as on the evaporator cooling capacity. The collector area was a more substantial parameter. An increase in the collector area resulted in lower COP values. Thus, from the model results it is recommended to choose a collector with lower area. The results are supported by the numerical studies of [12] showing that optimum COP values are achieved for ammonia concentrations ranging between 0.3 to 0.45 . Also the theoretical work of [12] has indicated that an increase in the generator yielded a reduction in the COP values.

\section{Acknowledgements:}

The research was funded by the Israeli Ministry of Energy.

$\begin{array}{ll}\text { Nomenclature } & \\ A & \text { Area }\left[\mathrm{m}^{2}\right] \\ C_{o} & \text { Distribution parameter } \\ D & \text { Pipe diameter }[\mathrm{m}] \\ f & \text { Circulation ratio } \\ g & \text { Gravity }\left[\mathrm{m} / \mathrm{sec}^{2}\right] \\ h & \text { Enthalpy }[\mathrm{kJ} / \mathrm{kg}] \\ H & \text { Motive head }[\mathrm{m}] \\ I & \text { Irradiance }\left[\mathrm{W} / \mathrm{m}^{2}\right] \\ L & \text { Length of the lift tube }[\mathrm{m}] \\ \dot{m} & \text { Mass flow rate }[\mathrm{kg} / \mathrm{sec}] \\ P & \text { Pressure }[\mathrm{Pa}] \\ Q & \text { Volumetric flow rate }\left[\mathrm{m}^{3} / \mathrm{sec}\right] \\ \dot{Q} & \text { Heat input applied at the generator } \\ T & \text { [W] } \\ V & \text { Temperature }\left[{ }^{\circ} \mathrm{C}\right],[\mathrm{K}] \\ X & \text { Velocity }[\mathrm{m} / \mathrm{sec}] \\ \text { Greek symbols } & \text { Quality } \\ \alpha & \text { Void fraction } \\ \eta & \text { Efficiency } \\ \xi & \text { Mass concentration } \\ \rho & \text { Density }\left[\mathrm{kg} / \mathrm{m}^{3}\right] \\ & \end{array}$

$\begin{array}{ll}\text { Subscripts } & \\ \text { A } & \text { Evacuated tube solar collector } \\ \text { abs } & \text { Absorber } \\ \text { amb } & \text { Ambiaent } \\ \text { c } & \text { Collector } \\ \text { cond } & \text { Condenser } \\ \text { DC } & \text { Downcomer } \\ \text { evap } & \text { Evaporator } \\ \text { G } & \text { Gas } \\ \text { gen } & \text { Generator } \\ \text { GM } & \text { Drift flux } \\ \text { L } & \text { Liquid } \\ \text { LT } & \text { Lift tube } \\ \text { m } & \text { mixture } \\ \text { poor } & \text { Poor solution } \\ \text { rec } & \text { rectifier } \\ \text { ref } & \text { Refrigerant } \\ \text { rich } & \text { Rich solution } \\ \text { TP } & \text { Two-phase } \\ 1,2, . .16 & \text { System points }\end{array}$




\section{References:}

[1] B.C. Von Platen and Munters C.G, "Refrigeration," US Patent US1678277A, 1928.

[2] A. Einstein, and L Szilárd "Refrigeration," US Patent 1781541, 1927

[3] A. Delano, "Design Analysis of the Einstein Refrigeration Cycle", Ph.D. Thesis, Georgia Institute of Technology, USA,1998

[4] D. Chisholm, "Two-phase flow in pipelines and heat exchangers". London; New York: G. Godwin in association with Institution of Chemical Engineers, 1983

[5] A. H. Stenning and C. Martin, "An Analytical and Experimental Study of Air-Lift Pump Performance", Journal of Engineering for Gas Turbines and Power, vol. 90, no. 2, pp. 106-112, Apr. 1968.

[6] A. Koyfman, M. Jelinek, A. Levy, and I. Borde, "An experimental investigation of bubble pump performance for diffusion absorption refrigeration system with organic working fluids", Applied Thermal Engineering, vol. 23, no. 15, pp. 1881-1894, Oct. 2003.

[7] N, Dammak N., Chaouachi, B., Gabsi S. and Bourouis M., "Optimization of the Geometrical Parameters of a Solar Bubble Pump for Absorption-Diffusion Cooling Systems", American Journal of Engineering and Applied Sciences. 3. 10.3844/ajeassp.2010.693.698, 2010.

[8] P. Vijayakumar, S. Kumar, S. Subramanian and R. Prakash, "Comparison of evacuated tube and flat plate solar collector - A review." World Wide Journal of Multidisciplinary Research and Development, pp. 3236, 2017.

[9] B. Gurevich B, "Theoretical Prediction of the Mass Flow Rates in the Bubble Pump". International Journal of Thermodynamics, Vol. 22, Issue 4, pp. 177-182, 2019.

[10] J. Freeman, A. Najjaran, R. Edwards, M. Reid, R. Hall R., A. Ramos A, and C.N. Markides, "Testing and simulation of a solar diffusion-absorption refrigeration system for low-cost solar cooling in India". In: Proc ISES Solar World Cong; Oct 29-Nov 2; Abu Dhabi, UAE, 2017.

[11] A. Zohar, M. Jelinek, A. Levy and I. Borde, "The influence of diffusion absorption refrigeration cycle configuration on the performance", Applied Thermal Engineering, Vol. 27, pp. 2213-2219, 2007.

[12] A. Zohar, M. Jelinek, A. Levy and I. Borde, "Numerical investigation of a diffusion absorption refrigeration cycle", International Journal of Refrigeration, Vol. 28, pp. 515-525, 2005.

[13] A. Zohar, M. Jelinek, A. Levy and I. Borde, "The influence of the generator and bubble pump configuration on the performance of diffusion absorption refrigeration (DAR) system", International Journal of Refrigeration, Volume 31, Issue 6, pp 962969, 2008.

[14] A. Zohar, M. Jelinek, A. Levy and I. Borde, ss" Performance of diffusion absorption refrigeration cycle with organic working fluids", International Journal of Refrigeration Vol.32, pp. 1241-1246, 2009.

[15] R.H. Bonnecaze, W. Erskine and E.J. Greskovich, "Holdup and pressure drop for two-phase slug flow in inclined pipelines", AIChE Journal, vol. 17, no. 5, pp. 1109-1113.

[16] ims.gov.il. [Online]. Available: https://ims.gov.il/en. [Accessed: 27-Feb-2021]. 